\title{
Fear of the shock side as a function of acquisition criterion in one-way avoidance
}

\author{
DENNIS J. DELPRATO \\ Eastern Michigan University, Ypsilanti, Michigan 48197
}

\begin{abstract}
Independent groups of rats were first trained to criteria of $1,3,9$, or 27 consecutive avoidances in a one-way task. Subsequently, fear of the shock side was measured in a nonshock passive avoidance test. Males showed progressively less fear of the shock side as the avoidance criterion was extended. Females produced a $U$-shaped function with maximum fear following nine consecutive avoidances. The results are consistent with previous experiments that obtained diminutions in fear with extended avoidance. Implications for theories of avoidance were discussed.
\end{abstract}

According to two-factor avoidance theory and the principle of anxiety conservation (Solomon \& Wynne, 1954), fear motivates avoidance, fear reduction reinforces instrumental avoidance responses, and CS fear is conserved (not extinguished) on avoidance trials. Therefore, CS fear should not diminish after even a large number of successful avoidances. However, Kamin, Brimer, \& Black (1963) found that fear elicited by the CS, as assessed with Estes and Skinner's (1941) conditioned suppression technique, increased as the number of consecutive avoidances increased from 1 to 9 , but dramatically decreased when the number of consecutive avoidances increased from 9 to 27 . Linden (1969) has extended Kamin et al's results by demonstrating that avoidance training to a criterion of 40 avoidances attenuated previously established conditioned suppression (fear) to the CS. Hoffman and Fleshler (1962), on the other hand, took concurrent measures of leverpress avoidance and suppression and reported no diminution of suppression over extended avoidance training.

The purpose of the present experiment was to determine the relation between fear of the shock side and amount of one-way avoidance training. This relation has not been previously reported for one-way avoidance. Also, the measure of shock-side fear was a modification of Page's (1955) passive avoidance test, not the suppression of appetitively maintained behavior that was used in the studies above.

\section{METHOD}

\section{Subjects and Apparatus}

The Ss were 16 male $(326-411 \mathrm{~g})$ and 16 female (200-229 g) rats of the Sprague-Dawley strain.

The apparatus had one white and one black $44.5 \times 10.2 \times$ $19.0 \mathrm{~cm}$ chamber separated by a $5.5-\mathrm{cm}$ hurdle. The entire floor was constructed of .32-cm-diam rods. Scrambled shock was provided by a Model 4008-J Scientific Prototype ac source set at $.7 \mathrm{~mA}$. A pressboard insert was placed over the grids of the safe side. The apparatus rested $18 \mathrm{~cm}$ off the floor of the experimental room, and $\mathrm{E}$ observed $\mathrm{S}$ through Plexiglas lids that comprised the ceiling of each compartment.

\section{Procedure}

After S spent $3 \mathrm{~min}$ in the apparatus undisturbed, it received pseudoavoidance (adaptation) trials until it met a criterion of three consecutive failures to leave the to-be-shock side within 10 sec.

Avoidance conditioning began after $\mathrm{S}$ met adaptation criterion. On each trial, $\mathrm{S}$ was placed in the rear of the shock side facing the hurdle. Shock was programmed to occur $5 \mathrm{sec}$ (avoidance interval) after $\mathrm{S}$ was released, unless it had entered the safe side. The shock was escapable on nonavoidance trials. The $\mathrm{S}$ spent the 30 -sec intertrial interval in the safe side after each escape or avoidance response. Since a door was not used, S could reenter the shock side during the intertrial interval; if this occurred, E began the next avoidance interval and the trial was scored as an S-initiated trial. Although S-initiated trials were rare (less than $1 \%$ of the trials), this procedure served to maximize the shock side-safe side discrimination. After $S$ met the appropriate avoidance criterion and had spent the usual $30 \mathrm{sec}$ in the safe side, it was placed in a neutral (wire)cage for $30 \mathrm{sec}$ prior to the test of shock-side fear.

The $\mathrm{S}$ was placed in the rear of the safe side facing the shock side, and $E$ recorded its maximum degree of approach to the shock side on a 9-point scale in 30 -sec intervals over a 15 -min test period. The floor of the safe side was marked off into three 7-cm-long areas beginning at the hurdle (Areas 4, 3, and 2, respectively) and a fourth area (Area 1), $24.5 \mathrm{~cm}$ long, furthest away from the hurdle. The scoring system was: 0 (in Area 1 facing away from the shock side); 1 (in Area 1 facing shock side); 2, 3, and 4 (in Areas 2, 3, and 4, respectively); 5 (front paws on hurdle); 6 (front paws on shock side, rear paws on safe side); 7 (front paws on shock side, rear paws on hurdle); 8 (all 4 paws on shock side). The position of S's front two paws was used for scores of $0-4$.

Four Ss of each sex were assigned to each of four acquisition criterion groups. These criteria were $1,3,9$, and 27 consecutive avoidance responses. One half the Ss of each sex were run with a black shock side and the other half were run with a white shock side to increase the generality of the findings.

\section{RESULTS AND DISCUSSION}

Males required a mean of 3.69 trials and females required a mean of 3.62 trials to meet the adaptation criterion on the pseudoavoidance trials $(\mathrm{F}<1)$. Rats running from the black to the white side met the adaptation criterion in significantly fewer trials than did rats running from the white to the black side (means = 1.62 and 5.69, respectively, $F=5.83$, df $=1 / 16$, $\mathrm{p}<.05$ ). Since this was the only significant effect of 
Table 1

Acquisition Means: Shock to One Avoidance (Top), Shocks to Criterion (Middle), and Number of Avoidances (Bottom)

\begin{tabular}{lcccc}
\hline & \multicolumn{4}{c}{ Acquisition Criterion } \\
\cline { 2 - 5 } Sex & 1 & 3 & 9 & 27 \\
\hline \multirow{4}{*}{ Shocks to One Avoidance } \\
Males & 4.75 & 5.25 & 4.00 & 3.60 \\
Females & 5.00 & 4.60 & 5.20 & 3.80 \\
& \multicolumn{4}{c}{ Total Shocks in Acquisition } \\
Males & 4.75 & 7.50 & 5.75 & 5.75 \\
Females & 5.00 & 6.75 & 6.75 & 7.75 \\
& \multicolumn{4}{c}{ Number of Avoidances } \\
Males & 1.00 & 4.00 & 11.00 & 29.25 \\
Females & 1.00 & 3.75 & 9.25 & 32.00 \\
\hline
\end{tabular}

shock-side color in the data, no further reference will be made to this variable. The four acquisition criterion groups were statistically equivalent in their performance during the adaptation trials $(\mathrm{F}<1)$.

The mean number of shock trials that $\mathrm{Ss}$ in the various groups received before the first avoidance response is presented in Table 1. No significant variability was obtained with these scores (all Fs $<1$ ), indicating that $\mathrm{Ss}$ in the different acquisition criterion groups and the two sexes were equivalent in avoidance learning ability. The total number of shocks required to meet the various acquisition criteria are also shown in Table 1 . The two sexes performed similarly $(F<1)$, and in spite of variations in stringency of the avoidance criterion, the four acquisition criterion groups did not reliably vary in total shocks received $(\mathrm{F}<1)$. This finding contrasts with Kamin et al's two-way avoidance data; their group trained to a criterion of one avoidance received considerably fewer shocks than did groups trained to criteria of 3,9 , and 27 consecutive avoidances. Males and females were comparable with regard to the number of avoidances (Table 1) in acquisition $(\mathrm{F}<1)$.

Each S's shock-side fear score was determined by summing its scores in the 30-sec intervals on the 15-min fear test. Thus, fear scores could range from 0 (maximum fear) to 240 (minimum possible fear). Figure 1 presents the mean fear scores of males and females in the groups trained to criteria of $1,3,9$, and 27 consecutive avoidances. While males showed progressively less fear of the shock side as the avoidance criterion was extended, females produced a U-shaped function with maximum fear following 9 consecutive avoidances. The acquisition criterion $(\mathrm{F}=4.61, \mathrm{df}=$ $3 / 16, p<.025)$, sex $(F=6.42, d f=1 / 16, p<.025)$, and Criterion by Sex interaction $(F=4.06$, df $=3 / 16$, $\mathrm{p}<.05)$ effects were significant. Sex comparisons at the different levels of the criterion variable revealed that females were significantly less fearful than males after one avoidance $(p<.001)$. Sex differences were not reliable at the remaining avoidance criteria. Individual comparisons among the males indicated that the 27 avoidance group was significantly less fearful than all of the other groups $(p<.05)$. Within the females, the following comparisons were significant at the .05 level: 1 vs 9,1 vs 3 , and 9 vs 27 .

The main finding of the present experiment is that shock-side fear dissipated over extended avoidance training. Fear was not "conserved" during the course of avoidance trials; thus, the present results, along with those of Kamin et al (1963) and Linden (1969), are not consistent with the notion of anxiety conservation (Solomon \& Wynne, 1954). It seems that an adequate account of maintained avoidance behavior must include mechanisms other than fear as the source of motivation and fear reduction as the reinforcing event. Recent theoretical attempts of Denny (1971) have already achieved this, and, furthermore, Denny's relaxation theory can account for the diminutions in shock-side fear observed in the present investigation.

Briefly, shock-side cues are assumed to function as an $S^{D}$ for the avoidance operant (Lockard, 1963); thus, avoidance can occur in the absence of evident fear. Denny (1971) accounts for reduced shock-side fear as a function of repeated performance of the avoidance response by assuming that relaxation, a fear-competing response that originally occurs in the safe side following termination of shock and removal of shock-side cues, backchains or generalizes to the shock area. Dreilinger (1973) has recently obtained direct evidence for the backchaining of relaxation in an experiment in which shock-side fear was reduced more following regular extinction than following shock-side blocking trials.

The interaction between sex and avoidance criterion found in the present study is difficult to interpret. It is noteworthy that Kamin et al's (1963) U-shaped function between avoidance criterion and fear was also obtained with female (hooded, not albino) rats. This interaction may lead one to speculation regarding pituitary-adrenocortical influences.

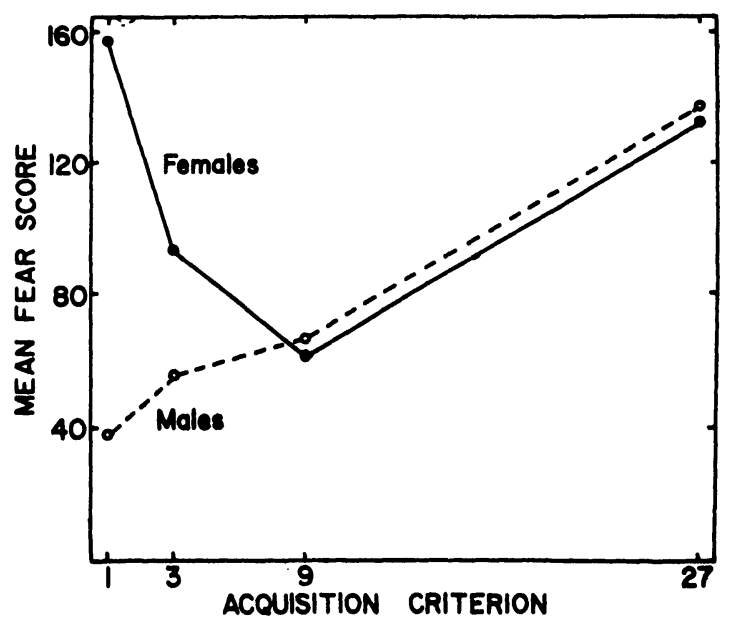

Fig. 1. Mean shock-side fear scores as a function of avoidance acquisition criterion. 


\section{REFERENCES}

Denny, M. R. Relaxation theory and experiments. In F. R. Brush (Ed.), Aversive conditioning and learning. New York Academic Press, 1971.

Dreilinger, C. The backchaining of relaxation in the elimination of active avoidance behavior in rats. Unpublished master's thesis, Eastern Michigan University, 1973.

Estes, W. K., \& Skinner, B. F. Some quantitative properties of anxiety. Journal of Experimental Psychology, 1941, 29,

Hoffman, H. S., \& Fleshler, M. The course of emotionality in the development of avoidance. Journal of Experimental Psychology, 1962, 64, 288-294.

Kamin, L. J., Brimer, C. J., \& Black, A. H. Conditioned suppression as a monitor of fear of the CS in the course of avoidance training. Journal of Comparative \& Physiological Psychology, 1963, 56, 497-501.
Linden, D. R. Attenuation and reestablishment of the CER by discriminated avoidance conditioning in rats. Journal of Comparative \& Physiological Psychology, 1969, 69, 573-5 78 .

Lockard, J. S. Choice of a warning signal or no warning signal in an unavoidable shock situation. Journal of Comparative \& Physiological Psychology, 1963, 56, 526-530.

Page, H. A. The facilitation of experimental extinction by response prevention as a function of the acquisition of a new response. Journal of Comparative \& Physiological Psychology $1955,48,14-16$

Solomon, R. L., \& Wynne, L. C. Traumatic avoidance learning: The principles of anxiety conservation and partial irreversibility. Psychological Review, 1954, 61, 353-385.

(Received for publication November 19, 1973.)

Bulletin of the Psychonomic Society

1974, Vol. $3(3 A), 168-170$

\section{Time off from rapid stimulation*}

\section{KENNETH S. KELEMAN $\dagger$ and BRUCE T. LECKART California State University, San Diego, Calif. 92115}

A study was conducted to test arousal theory predictions about exploratory behavior in high-stimulation environments. The effect of rapidly changing visual and auditory stimulation on the duration of subsequent S-controlled perceptual deprivation or "time off" from stimulation was investigated. Eighteen Ss were repeatedly exposed to periods of 3,15 , or $30 \mathrm{sec}$ of repadly changing stimulation followed by S-terminated time off. Results showed that time off was longest after short $(3 \mathrm{sec})$ presentations and shortest after long $(30 \mathrm{sec})$ presentations. The results, which failed to support a hypothesis derived from arousal

*The authors would like to thank R. M. Yaremko, Alice Cochran, and Mark Butler for their assistance.

+ Now at the University of Utah. Reprint requests should be sent to Psychology Department, University of Utah, Salt Lake City, Utah 84112 . theory notions, were discussed alternatively in terms of limits of sensory input and task demands. The finding of an increase in rate of stimulus change over trials was explained in terms of arousal decrease.

Theoretical explanations of attentional or exploratory behavior under conditions of reduced sensory input have frequently centered around notions of arousal (see e.g., Berlyne, 1960; Fiske \& Maddi, 1961; Schultz, 1965; Leckart, Butler, \& Yaremko, 1972). Using deprivation experimental paradigms, these authors and other have provided considerable evidence to support the central theoretical notions that: (a) an organism attempts to maintain an optimal level or arousal, and (b) stimulation produces arousal. By contrast, there have been few tests of these notions which have used sensory overload or overstimulation experimental paradigms. Furthermore, the overstimulation results reported so far have not 